\title{
More Light and Less Heat \\ Mirowski on Economics and the Energy Metaphor
}

\author{
D. WADE HANDS \\ University of Puget Sound
}

I initially approached More Heat than Light with some apprehension. This is not because I suspected that I would disagree with its main thesis but because I feared that I would find the book anticlimactic. Over the past few years, Phil Mirowski has served us a number of delightful appetizers ${ }^{1}$ - so many in fact that I suspected I might tire of the taste before the main entrée appeared. These concerns were wholly unfounded. The main entree has finally arrived and is of such depth and complexity that it makes the appetizers, well, just appetizers.

Mirowski's central thesis is that neoclassical economics-initially developed during the 1870 s and currently the dominant paradigm in economic theory-amounts to little more than a "brazen daylight robbery" (p. 4$)^{2}$ of nineteenth-century energy physics. Motivated by the desire to achieve the status and prestige of the physical sciences, early neoclassical economists created their "revolution" by simply substituting "utility" for "energy" in the physics of their day. In a limited respect, this project was successful-the mathematical formalism of energy physics did (and does) contribute to the scientific respectability of the neoclassical research program-but this status was achieved at substantial cost. Mirowski argues that there were (and are) deep problems associated with the economic appropriation of the energy metaphor; physical systems have properties that make the mathematics appropriate, but these properties are not shared by economic systems. For example, the physical requirement that potential energy and kinetic energy sum to a constant translates into the economic requirement that utility and income sum to a constant. This is a problem because utility and income are measured in entirely different units. Mirowski argues that such difficulties were exacerbated by the scientific naíveté of the early neoclassical economists 
who were trained in science and engineering - they had been exposed to the basic ideas of energy physics - but their knowledge was relatively rudimentary (p. 250). The result was energy physics appropriated in a "shoddy and slipshod manner" (p. 108).

Mirowski provides a detailed discussion of how this misappropriation of the energy metaphor has surreptitiously influenced the development of modern economic thought. He reconstructs and explains certain generally accepted facts of theoretical life in economics (such as the problems of neoclassical production theory) and exposes some of the fundamental weaknesses of neoclassical theory (such as its inability to explain preference changes). Mirowski also argues that the dominance of the energy metaphor from nineteenth-century physics has prevented economists from taking advantage of more recent developments in physical theory, such as quantum mechanics and the theory of relativity. The result, according to Mirowski, is

a tale reminiscent of Dorian Gray .... Neoclassicals, by imbibing some mystical elixir of modern mathematical techniques, have maintained the figure of vibrant youth, while hidden away somewhere in the attic is the real portrait, the original metaphor of a conserved preference field in an independently constituted commodity space, growing progressively desiccated and decrepit. (p. 374)

My overall evaluation of Mirowski's thesis is quite positive. Ibelieve that he is entirely correct about the role of the energy metaphor in early neoclassical economics (probably reaching an apogee in Irving Fisher), and he is also correct that the metaphor has been lurking ever since in the background of neoclassical economics. The energy metaphor and its mathematics have been actively influential in the development of modern neoclassical theory, although I would probably weaken its impact from Mirowski's story by saying "influenced" whereas Mirowski would say "dominated."

Where I mainly differ from Mirowski is on the implications of his thesis. For Mirowski, uncovering this hidden influence amounts to a scathing critique of modern neoclassical economics (and given the neoclassical dominance of the profession, this means most of modern economics). For him, the metaphor and its mathematics have been both dominant and pernicious. I disagree. While I am convinced that Mirowski has uncovered something important that can be used to further our understanding of the development of modern economic theory, I am not convinced that his thesis entails the kind of critical bite that he would like it to have. 
Given this overall evaluation of More Heat than Light, I will divide my comments into two sections. The first-more light-lends additional support to Mirowski's general historical thesis by using it to illuminate two areas of modern neoclassical economics that Mirowski does not emphasize. The second-less heat-offers some arguments against Mirowski's critical interpretation of his general thesis.

\section{MORE LIGHT}

One of Mirowski's main technical arguments (pp. 222-54, 369-71) is that the so-called "integrability" conditions from neoclassical demand theory restrict prices to be a conservative vector field. Mathematically, if the price vector $p$ is a conservative field, then it is the gradient of some underlying potential function $U$, and we have $p=$ $\nabla U$. In the neoclassical interpretation, this potential function would represent "utility." In physics, the force vector $F$ is the primitive (p. 223), and when $F$ is a conservative field, then it can be written as $F=\nabla U$, where $U$ is potential energy. Thus, Mirowski argues, "utility" is nothing more than the neoclassical surrogate for potential energy in physics.

This "core physics metaphor of utility as potential energy" (p. 358) is the root of the problem for Mirowski. Applying the metaphor rigorously would mean that utility functions would inherit all of the properties of potential energy: path independence, temporal reversibility, and, most important, conservation principles. But each of these properties is problematic in an economic context: Path independence implies that the level of utility is independent of the order in which the goods are consumed, temporal reversibility implies that preferences cannot be changed by consumption, and conservation principles (the real problem) imply the conservation of utility, expenditure, or their sum (pp. 273-74). Mirowski argues that because of these unsatisfactory implications the integrability conditions have been treated as an arcane mathematical property not connected in any systematic way to the main neoclassical program. "The befuddled treatment of the neoclassical integrability conditions should call into question the entire project of portraying utility as potential energy; in other words, they should undermine the entire neoclassical project of imitating physics" (p. 371).

I will twist Mirowski's argument slightly and use it to explain two episodes in the history of post-World War II neoclassical economics. 
In telling my story, I disagree slightly with Mirowski's interpretation of integrability, but my overall discussion lends additional support to his general historical thesis that when we view through the filter of the energy metaphor we can "see" what has gone on in neoclassical economics much more clearly. My argument requires some mathematical symbolism.

Let $x_{i}(p, M)$ represent an individual's (differentiable) demand function for goods $i=1,2, \ldots, n$. The competitive prices of the $n$ goods are given by the vector $p=\left(p_{1}, p_{2}, \ldots, p_{n}\right)$ and the scalar $M$ represents the money income of the individual. All prices and money income are strictly positive. As is standard in neoclassical demand theory, the $n$ demand functions $x_{1}(p, M), x_{2}(p, M), \ldots, x_{n}(p, M)$ are the solutions to the utility maximization problem,

$$
\begin{gathered}
\max \cdot \sum_{n}^{U}(x), \\
\text { subject to } \sum_{i=1}^{n} p_{i} x_{i}=M .
\end{gathered}
$$

The utility function $U(x)$ is differentiable and has sufficient structure to guarantee that a maximum exists; the budget constraint is that the total expenditure on the $\mathbf{n}$ goods cannot exceed the available money income $(M)$. The maximization problem has $n$ choice variables $x=\left(x_{1}\right.$, $\left.x_{2}, \ldots, x_{n}\right)$ and one (linear) constraint. The problem has $n+1$ parameters, the $n$ prices, and money income $M$. The partial derivative $\partial x_{i} / \partial p_{i}$ represents the change in the demand for good $\mathrm{i}$ caused by a change in its "own" price, $\partial x_{i} / \partial p_{j}$ for $j \neq i$ represents the change in the demand for good $i$ caused by a change in the price of some other good $j$, and $\partial x_{i} / \partial M$ represents the change in the demand for good i caused by a change in money income. The demand functions $x_{i}(p, M)$ are the "direct" or "regular" demand functions and represent the utilitymaximizing quantities as a function of the prices. When these direct demand functions are invertible, they can be written as the "indirect" or "inverse" demand functions $\mathrm{p}_{\mathrm{i}}(\mathrm{x}, \mathrm{M})$, with the price being a function of the quantities consumed.

The "integrability" question as it is normally presented in neoclassical economics reverses the above utility maximization problem. ${ }^{3}$ Instead of starting with the utility function $U(x)$ and finding the relevant $x_{i} s$ that solve the utility maximization problem, the integrability problem starts with the $x_{i} s$ and then asks if such $x_{i} s$ could be a solution to some utility maximization problem (i.e., when utility can 
be "recovered" from demands). There are a number of integrability conditions (which guarantee such recovery) in the literature, but the most frequently discussed is Samuelson's (1950). Samuelson demonstrated that if the matrix of "substitution terms" given by

$$
S_{i j}=\partial x_{i} / \partial_{p j}+x_{j} \partial x_{i} / \partial M
$$

is symmetric (if $S_{i j}=S_{i i}$ for all $i, j$ ) and negative semidefinite, then the demand functions are integral.

This integrability condition (S) is mathematically the condition for a conservative vector field, but it is not exactly what is necessary for prices to be the gradient of a conservative potential utility field. ${ }^{4}$ What is necessary to have $p=\nabla U$ (Mirowski's "core physics metaphor") is the symmetry of the Jacobian of the inverse demand functions, that is, for

$$
\partial \mathrm{p}_{\mathrm{i}} / \partial \mathrm{x}_{\mathrm{j}}=\partial \mathrm{p}_{\mathrm{j}} / \partial \mathrm{x}_{\mathrm{i}} \text { for all } \mathrm{i}, \mathrm{j} \text {. }
$$

If this symmetry condition holds, then the inverse demand functions (the price vector written as a function of the quantities of the goods) form a conservative vector field and $p=\nabla U$, that is, $p_{i}(x)=\partial U / \partial x_{i}$ for all $i$. In this case, the (inverse) demand function is the marginal utility function, and this certainly seems to be what the early neoclassical economists had in mind, however unclear they were about it. Mirowski is entirely correct that neoclassical economists wanted to mimic energy physics and that a symmetry condition like $(S)$ is required to translate utility theory term by term into physical theory: I simply disagree that the standard integrability condition (S) is sufficient for the job. ${ }^{5}$

One might suspect that I am being unduly technical here, but I will use this difference between (S) and $(J)$, to argue-consistent with Mirowski's general thesis-that important developments in the history of neoclassical economics can best be understood as problems associated with the translation of the energy metaphor. More specifically, I will discuss two theoretical problems which developed precisely because the integrability condition (S) was not sufficient to actually complete the metaphor. The term-by-term translation of utility into potential energy requires a stronger condition like (J); but the weaker integrability condition (S) which was assumed does not allow the full translation. Thus the profession desperately wanted to exploit fully the metaphor-as Mirowski argues-but could not do so because of the undesirable implications that Mirowski discusses and 
also because such complete exploitation would require a much stronger and empirically falsifiable (and false) symmetry condition like $(\mathcal{J}){ }^{6}$ The resulting tension created by wanting to exploit fully the metaphor, but being unable to do so has formed the backdrop to a number of theoretical problems in modern neoclassical economics.

One problem is the so-called "correspondence principle" between dynamic stability and determinate comparative statics popularized by Paul Samuelson (1941, 1942, 1947). The correspondence principle was supposed to demonstrate a simple one-to-one relationship between the stability of the price adjustment mechanism and the signs of the comparative statics expressions associated with arbitrary changes in the system's parameters. The type of dynamic system that Samuelson considered was the (now) standard Walrasian tatonnement adjustment mechanism, the kind of "jerry-built" (p. 251) dynamic model that Mirowski considers an "outrageously rococo and inconsistent" (p. 240) contraption. This adjustment mechanism is written as the following system of $\mathbf{n}$ ordinary differential equations,

$$
d p_{i}(t) / d t=k_{i} z_{i}[p(t)] \text { for } i=1,2, \ldots, n,
$$

where $t$ represents time, $p(t)=\left[p_{1}(t), p_{2}(t), \ldots, p_{n}(t)\right]$ is the price vector, $z_{i}[p(t)]$ is the market excess demand vector (total market demand minus total market supply), and $k_{j}$ is the (scalar) adjustment speed for the ith market. The mechanism $(T)$ is designed to capture the intuitive idea that prices will increase when demand is greater than supply and fall when supply is greater than demand; of course, at the equilibrium price vector $p^{*}=\left(p_{1}^{*}, p_{2}{ }^{*}, \ldots, p_{n}{ }^{*}\right)$ where $z_{i}\left(p^{*}\right)=0$ for all $i$, the prices no longer change with time and $d p_{i} / d t=0$ for all i. The local stability of the system (T)-Samuelson only considered local stability-implies that for initial nonequilibrium price vectors "close" to equilibrium, the system "converges to" the equilibrium price vector, that is, $\mathrm{p}(\mathrm{t}) \rightarrow \mathrm{p}^{*}$ as $\mathrm{t} \rightarrow \infty$. The comparative statics question, on the other hand, is the question of how the equilibrium prices $\left(p^{*}\right)$ change when some parameter (say, b) in the system changes. Qualitative comparative statics information would be information about the signs of the comparative statics expressions,

$$
\partial p_{i}^{*} / \partial b \text { for all } i=1,2, \ldots, n \text {. }
$$

Samuelson's correspondence principle implied that such qualitative comparative statics information would be available in general if the system were stable (and vice versa). ${ }^{9}$ 
Although Samuelson's correspondence principle has been shown to hold in a number of special cases, it does not hold in general. ${ }^{10}$ These results (or absence of results) led Arrow and Hahn (1971) to assert that "the correspondence principle isn't" (p. 321). This failure of the correspondence principle can be explained in a way that is quite consistent with Mirowski's general thesis about the energy metaphor. The standard assumption on the excess demand functions in (T) include the integrability conditions (S). If the model is a pure exchange economy with no production, then the excess demands are simply the demands (the total $x_{i} s$ in the market) minus a fixed quantity: that is, $z_{i}(p)=x_{i}(p)-\bar{x}_{i}$, where $\bar{x}_{i}$ is the fixed supply of good $i$. If there is production, then the supply of the good $\left(s_{i}\right)$ will also be a function of the prices, so the excess demands will be given by $z_{i}(p)=x_{i}(p)-s_{i}(p)$. In either case, the integrability condition $(S)$ is a substantial restriction on the functions in the dynamical system (T). ${ }^{11}$ The problem-and this is why the correspondence principle "isn' $t$ " -is essentially that (S) and the other standard restrictions are not strong enough to guarantee the connection between stability and comparative statics in the way that Samuelson desired. On the other hand, the stronger symmetry condition $(\mathrm{J})$, the condition that would allow a one-to-one translation of utility theory into energy physics, is sufficient to guarantee that the correspondence principle holds. ${ }^{12}$ The energy metaphor suggests a correspondence principle which would be a very desirable result, but to have it, the translation would need condition (J), which was theoretically unacceptable. The literature on the correspondence principle in general equilibrium theory was basically an attempt to circumvent this issue, to obtain the results that would be available if the metaphor were strictly applied but to do so without the unsavory implications of strictly applying it.

The second theoretical problem illuminated by the "energy metaphor" is in the Debreu-Mantel-McFadden-Mas-Colell-Richter-Sonnenschein literature on excess demand functions. ${ }^{13}$ The basic problem is that the standard neoclassical assumptions on utility maximizing agents, including the integrability condition (S), place almost no restrictions on the behavior of aggregate (market) demand functions or excess demand functions. With almost no restrictions on the excess demand functions, it is very easy to have multiple equilibria (more than one $p^{*}$ such that $z_{i}\left[p^{*}\right]=0$ for all $\left.i\right)$, unstable equilibria ( $p^{*}$ that will not be reached by $[T])$, and other difficulties. Again, if the metaphor could be completed with the imposition of a stronger restriction like (J), then 
such problems would not occur. If $(J)$ were imposed in a pure exchange economy, then there would exist a potential function $U$ such that $z(p)=\nabla U(p)$ and the tâtonnement mechanism $(T)$ would become a gradient system; such systems have relatively simple dynamic properties. ${ }^{14}$ In this case, the economy would "really" behave like the physical systems of energetic physics. Of course, stronger conditions like $(J)$ cannot be imposed, and economic theory continues to live with the resulting tension.

\section{LESS HEAT}

Mirowski has clearly isolated an important factor contributing to the pattern of neoclassical theory development. Neoclassical economists from the beginning wanted to exploit the metaphor but could not because to exploit it fully would reveal how inappropriate the exploitation actually was. For Mirowski, this "reveals the predicament of neoclassical theory in the twentieth century. The imperatives of the orthodox research program leave little room for maneuver and less room for originality; the individual elements of the mandate do not add up to a coherent research program" (p. 387). Chapter 7 ("The Ironies of Physics Envy") is concerned exclusively with these difficulties - exposing the ways in which the dominant energy metaphor has prevented neoclassical economics from generating an adequate theory of value or economic behavior. Mirowski finds some "distinctly hopeful turns," but "each of these innovations has been obstructed by the dominant conception of economic value rooted in the imitation of physics" (p. 10). Mirowski finds the disease to be quite severe and the prognosis bleak:

In the absence of the metaphor of utility as nineteenth-century potential energy, there is no alternative theory of value, no heuristic guide to research, no principle upon which to base mathematical formalism, no causal invariant in the Meyersonian sense, and most threatening, no basis for the claim that economics has become scientific. (p. 368)

I do not find the disease to be nearly as severe nor the prognosis as bleak. The energy metaphor does lurk in the background of neoclassical economics, and the tension it creates has influenced the development of the program; however, the grip is simply not as tight nor as pernicious as Mirowski suggests. 
First, neoclassical economics has not been dominated by a single metaphor; rather, it has been influenced by different metaphors, each pulling and pushing in its own particular direction. Neoclassical economics is metaphorically an ensemble-or in the mathematical language of neoclassical economics, a convex combination of a number of metaphorical influences. One of the most influential metaphors is the "invisible hand," the idea that each individual economic agent acting in his or her own self-interest will bring about the best possible social outcome..$^{15}$ The invisible hand metaphor has played an important role in the development of both classical and neoclassical economics. Often, the invisible hand metaphor and the mathematics of the energy metaphor push in the same direction, as in the case of the standard efficiency theorems for competitive equilibria--but sometimes they do not. Sometimes, the utility maximization of individual agents is inconsistent with the welfare maximum-sometimes, the "planner's problem" conflicts with the path generated by a competitive equilibrium; sometimes, there are externalities and public goods; and sometimes, there are increasing returns to scale. Mirowski is correct that the energy metaphor has been an important influence, but it is certainly not the only metaphorical influence.

Second, Mirowski focuses exclusively on the energy metaphor. Given the nature of the relationship between nineteenth-century energy physics and neoclassical economics, metaphor is the correct term, but neoclassical economics is also influenced by metaphysical ideas that cannot be labeled metaphors. Watkins (1958) calls such metaphysical notions that exert an influence on the development of a scientific theory "confirmable and influential metaphysics." Such metaphysical ideas are not falsifiable (not scientific by Popperian standards), but they do have empirical implications; one of Watkins's often cited examples is "every event has a cause." Although such "doctrines cannot be experimentally overthrown they do clash with, and so forbid the construction of, related empirical hypotheses. This enables them to play a regulative role" (Watkins 1958, 345).

Mirowski does consider such "confirmable and influential metaphysics" in an indirect way when he discusses the "Laplacian Dream of a determinate universe" (p. 65): the belief that it would be possible to find a "single mathematical formula that described the entire world" (p. 28). While the Laplacian Dream is precisely a Watkins-type influential metaphysical doctrine, it is not the only metaphysical 
doctrine at work in neoclassical economics; others, unlike the Laplacian Dream, are more unique to economics. Mirowski tries to wrap up all such influential metaphysics into the Laplacian Dream, attach it snugly to energetic physics, and then subsume it all under the energy metaphor. But this just doesn't work. First, it is not clear that utility theory is even consistent with (much less implied by) the Laplacian Dream. After all, utility is an inherently intentional notion and intentions are uniquely human. A very good argument could be made that the Laplacian Dream requires the complete reductionism of a philosophical position like eliminative materialism; that is, it requires that the "actions" of economic agents be completely reduced to physical processes in the human brain. ${ }^{16}$ Second, and more important, there are many other metaphysical influences in the history of neoclassical economics (some shared by classical economics and some unique to neoclassicism) that cannot be legitimately bundled up with the purported meta-metaphysic of the Laplacian Dream.

One of these important metaphysical ideas is individualism-the idea that only individuals, not holistic or social entities, are the causes of economic processes. While much ink has been spilled over the question of how the metaphysic of individualism influences neoclassical economics-is it merely "methodological" individualism or is it epistemological individualism or ontological individualism or possibly psychologism?-neoclassical economics is individualist in its approach. The metaphysic of individualism need not conflict with the Laplacian Dream, but it need not be implied by it either.

The pull of individualism is strong in Austrian economics, which Mirowski considers nonneoclassical (p. 260-61), but it is also strong in the Chicago school, a school that even Mirowski must consider neoclassical. In fact, the battle for dominance between the Laplacian Dream/energy metaphor that Mirowski emphasizes and the methodological individualism of an earlier, less mathematical type seems to be the best way to divide the new Chicago school (e.g., Lucas) from the older Chicago school (e.g., Stigler, Becker, and Friedman). ${ }^{17}$ Donald McCloskey (1988) also makes this point in his response to Mirowski:

The attacks from various quarters on neoclassical economics seem to depend on a misapprehension of its core. A notion that important social forces arise out of self-interested behavior and that these forces are hedged about by entry and competition is plausible on its face and perfectly healthy as a program in economics. Along with some parallel 
and very different programs, it has been going strong since the eighteenth century. It explains many of the social facts we wish to explain, from the rise of real wages since 1840 to the difficulties of big bankers in the 1980s. I sometimes wonder if the critics of neoclassicism know what they are talking about, literally. They seem to identify neoclassical economics with Paul Samuelson's youthful enthusiasm for identifying economics with constrained maximization, embodied now in dozens of intermediate and graduate texts. I wonder if the critics have read enough real price theory from the hands of the masters, such as Armen Alchian or Ronald Coase. (p. 291)

There are other metaphors influencing neoclassical economics and there are metaphysical influences on neoclassical economics other than those which could properly be called metaphors. In addition to these metaphorical and metaphysical influences, neoclassical economics has undoubtedly been influenced by empirical evidence. By saying "influenced by empirical evidence" I certainly do not mean that the development of neoclassical economics fits neatly into any simple empirical framework for the growth of scientific knowledge such as Popperian falsificationism. I mean that in some not yet clearly specified way, neoclassical economics is broadly consistent with the empirical evidence of individual and market behavior. When neoclassical economists wrote down the "jerry-built" adjustment scheme (T), they did not write it as $d p_{i} / d t=-k_{i} z_{i}[p(t)]$; to do so would mean that prices increase when supply is greater than demand and decrease when demand is greater than supply. This simply is not the case in the vast majority of observed markets. Correspondence to "the facts" is most assuredly not the only criteria for theory choice in economics (as certain methodologists would argue it should be) but "the evidence," at least of a casual empirical sort, must surely be added to the mixture along with the metaphors and the metaphysics if we are going to have any hope of reproducing the actual history of the neoclassical program. For the complete story, it may also be necessary to include the sociological, psychological, and political factors from the sociology of science. How much metaphor, how much metaphysics, how much data, how much politics? In general, I do not know. For a particular episode in the history of neoclassical thought, I might be able to give you some rough proportions, but in general, I do not know. My point is simply that it is not all or, in most cases, substantially the energy metaphor. 


\section{CONCLUSION}

The energy metaphor clearly matters to the development of neoclassical economics, from its inception on to the most recent journal articles. Other authors may have hinted at the influence of the energy metaphor, but Mirowski has convincingly demonstrated it. More Heat than Light is a detailed, careful, and ultimately convincing story. Mirowski is no doubt correct about the early neoclassical economists, Jevons and Fisher in particular, and the case for Samuelson's attempt to exploit the metaphor is well documented. As I tried to demonstrate in my section on "more light," the thesis has the potential to unpack even more areas in the history of neoclassical economics than Mirowski has provided in his study. All in all, it is generally a convincing story.

In my "less heat" section I argued not that Mirowski's thesis was unconvincing but that he overstates its critical importance. Many, many things have played a role in the evolution of the neoclassical research program. Mirowski has uncovered something new and something very important, but it is not the whole story. Different factors have exerted pressure on the development of neoclassical economics at different times and in different ways. No doubt there are episodes (Fisher's dissertation for one) where the energy metaphor was by far the dominant influence; there are other times when it was much less important. Whig history is no more acceptable when it is told from the perspective of a dominant metaphor than when it is told from the perspective of a narrow epistemological position. There have been many influences on the development of neoclassical economics: some good, some bad, and some uncertain. The point is to accurately identify the important ones and evaluate their relative significance. Mirowski has isolated an important influence, but it is certainly not the only one.

\section{NOTES}

1. See Mirowski (1984a, 1984b, 1986, 1987, 1988, 1989b) as examples.

2. Page numbers given without a specific reference refer to Mirowski's (1989a) More Heat than Light.

3. A brief discussion of integrability is given in any standard microeconomic theory text (e.g., Varian 1984). An excellent survey of the literature on integrability is provided by Hurwicz (1971). 
4. Actually, the integrability condition guarantees that the so-called "compensated" demand functions form a conservative vector field; their potential function is the "expenditure function" (e.g., see Varian 1984, 123).

5. That is, it is not sufficient in the general case; there are a number of specific special cases-homothetic preferences, vanishing income effects, and so on-where the two conditions (S) and $(\mathrm{J})$ are equivalent.

6. For a utility-maximizing consumer, the condition (J) has a number of empirical implications that are generally false. One of these is that all goods would have the same income elasticity.

7. This Walrasian tâtonnement adjustment mechanism is the most common framework for discussing neoclassical price dynamics, but others include the Hahn-Negishi process and the Fisherian arbitrage model. Arrow and Hahn (1971) survey the Walrasian tâtonnement literature in chapters 11 and 12 and the Hahn-Negishi process in chapter 13; the Fisher model is presented in Fisher (1983).

8. Qualitative comparative statics information is about the signs of these terms; quantitative comparative statics information is about the magnitude of these terms.

9. This discussion of the correspondence principle couches it solely in terms of the Walrasian general equilibrium model. Actually, Samuelson intended it to hold more generally, in Keynesian models for instance.

10. The cases where it does hold are surveyed in chapter 6 of Quirk and Saposnik (1968).

11. Actually, when the issue is the stability of (T), it is sufficient to focus on the pure exchange case because the production side is not generally destabilizing. Under standard assumptions, instability initiates from income effects on the demand side-the $\mathrm{x}_{\mathrm{j}} \partial \mathrm{x}_{\mathrm{j}} / \partial \mathrm{m}$ terms in (S)-not the production side (see Mukherji 1974, 248-49).

12. See Samuelson (1941, 110-11; 1947, 140-41, 271-72).

13. Debreu (1974), Mantel (1977), McFadden et al. (1974), and Sonnenschein (1973). This literature is surveyed in Shafer and Sonnenschein (1982) and summarized compactly in Mas-Colell (1985).

14. See Hirsch and Smale (1974, 199-203).

15. The importance of this "invisible hand" theme is emphasized by Ingrao and Israel (1990).

16. Or possibly the complete reduction to biological processes which then supervene on physical laws-an argument one might get combining Rosenberg (1981) and (1985).

17. See Hoover (1984).

18. McCloskey makes a similar point in his dialogue with Klamer (see Klamer and McCloskey 1989, 150-53) when he responds to Klamer's Mirowski-like attempt to fit all of the Chicago school, old and new, into "Samuelson's max U" (p. 151) framework.

\section{REFERENCES}

Arrow, K. J., and F. H. Hahn. 1971. General competitive analysis. San Francisco: Holden-Day. Debreu, G. 1974. Excess demand functions. Journal of Mathematical Economics 1:15-21.

Fisher, F. M. 1983. Disequilibrium foundations of equilibrium economics. Cambridge: Cambridge University Press. 
Hirsch, M. W., and S. Smale. 1974. Differential equations, dynamical systems, and linear algebra. New York: Academic Press.

Hoover, K. D. 1984. Two types of monetarism. Journal of Economic Literature 22:58-76.

Hurwicz, L. 1971. On the problem of integrability of demand functions. In Preferences, utility and demand, edited by J. S. Chipman, L. Hurwicz, M. K. Richter, and H. F. Sonnenschein, 174-214. New York: Harcourt Brace Jovanovich.

Ingrao, B., and G. Israel 1990. The invisible hand: Economic equilibrium in the history of science. Cambridge: MIT Press.

Klamer, A., and D. McCloskey. 1989. The rhetoric and disagreement. Rethinking Marxism 2:140-61.

Mantel, R. R. 1977. Implications of microeconomic theory for community excess demand functions. In Frontiers of quantitative economics IIIA, edited by M. D. Intriligator, 111-26. Amsterdam: North-Holland.

Mas-Colell, A. 1985. The theory of general economic equilibrium. Cambridge: Cambridge University Press.

McCloskey, D. N. 1988. The consequences of rhetoric. In The consequences of economic rhetoric, edited by A. Klamer, D. N. McCloskey, and R. M. Solow, 280-93. Cambridge: Cambridge University Press.

McFadden, D., A. Mas-Colell, R. Mantel, and M. K. Richter. 1974. A characterization of community excess demand functions. Journal of Economic Theory 9:361-74.

Mirowski, P. 1984a. The role of conservation principles in twentieth-century economic theory. Philosophy of the Social Sciences 14:461-73.

.1984b. Physics and the marginalist revolution. Cambridge Journal of Economics 8:361-79.

1986. Mathematical formalism and economic explanation. In The reconstruction of economic theory, edited by P. Mirowski, 179-240. Boston: Kluwer-Nijhoff.

1987. Shall I compare thee to a Minkowski-Ricardo-Leontief-Metzler matrix of the Mosak-Hicks type? Economics and Philosophy 3:67-96.

1988. The sciences were never at war? Some early skirmishes between physicists and economists. In Against mechanism, edited by P. Mirowski, 31-44. Totowa, NJ: Rowman \& Littlefield.

.1989a. More heat than light: Economics as social physics, physics as nature'seconomics. Cambridge: Cambridge University Press.

1989b. 'Tis a pity econometrics isn't an empirical endeavor: Mandelbrot, chaos, and the Noah and Joseph effects. Ricerchie Economiche 43:76-99.

Mukherji, A. 1974. Stability in an economy with production. In Trade, stability and macroeconomics: Essays in honor of Lloyd Metzler, edited by P. A. Samuelson, 243-58. New York: Academic Press.

Quirk, J., and R. Saposnik. 1968. Introduction to general equilibrium theory and welfare economics. New York: McGraw-Hill.

Rosenberg, A. 1981. Sociobiology and the preemption of social science. Baltimore: Johns Hopkins University Press.

1985. The structure of biological science. Cambridge: Cambridge University Press.

Samuelson, P. A. 1941. The stability of equilibrium: Comparative statics and dynamics. Econometrica 9:97-120.

1942. The stability of equilibrium: Linear and nonlinear systems. Econometrica 10:1-25.

-1947. Foundations of economic analysis. Cambridge, MA: Harvard University Press. 
1950. The problem of integrability in utility theory. Economica 17:355-85.

Shafer, W., and H. Sonnenschein. 1982. Market demand and excess demand functions. In Handbook of mathematical economics, Vol. 2, edited by K. J. Arrow and M. D. Intriligator, 671-93. Amsterdam: North-Holland.

Sonnenschein, H. 1973. Do Walras' identity and continuity characterize the class of community excess demand functions? Journal of Economic Theory 6:345-54.

Varian, H. R. 1984. Microeconomic analysis. 2d ed. New York: Norton.

Watkins, J.W.N. 1958. Confirmable and influential metaphysics. Mind 67:344-65.

D. Wade Hands is a professor of economics at the University of Puget Sound. His research interests include economic methodology and the history of modern economic thought. A collection of his papers on Popperian economic methodology, Testing, Rationality and Progress: Essays on the Popperian Tradition in Economic Methodology, is forthcoming from Rowman and Littlefield. 